\title{
Call for more Lyme disease research
}

- Cite as: CMAJ 2017 September 25;189:E1218. doi: 10.1503/cmaj.109-5476

Posted on cmajnews.com on Sept. 6, 2017.

anada urgently needs more research on Lyme disease to prevent it from reaching levels seen in the United States, according to Tara Moriarty, a University of Toronto researcher who studies how the Borrelia burgdorferi bacteria that cause the disease are disseminated in blood. She is one of only two full-time Lyme researchers funded by the Canadian Institutes of Health Research (CIHR).

Lyme disease cases in Canada have tripled from 338 cases in 2012 to 987 cases in 2016. This official count may be low, as patient groups contend that the disease is underdiagnosed.

Canada's numbers are far lower than those in the US, where at least 30000 cases are reported each year. That figure, however, accounts for only a fraction of actual cases, according to the Centers for Disease Control and Prevention, which estimates that about 300000 Americans are diagnosed with Lyme disease each year.

The Canadian federal government recently promised $\$ 4$ million for a Lyme disease research network. Canada's few Lyme disease researchers say the funding is welcome, but some are concerned there isn't enough for the research itself.

Still, Moriarty appreciates the money for a network, announced in late May. The funding follows the enactment of a private member's bill by Green Party Leader Elizabeth May, which required the government to hold a conference involving provincial governments and patient groups, as well as to set a federal framework for the disease. The conference was held last spring and the ensuing framework promised a research network.

The $\$ 4$ million will be spent over four years, beginning in 2018, according to the Public Health Agency of Canada (PHAC). That's apart from the research budget for

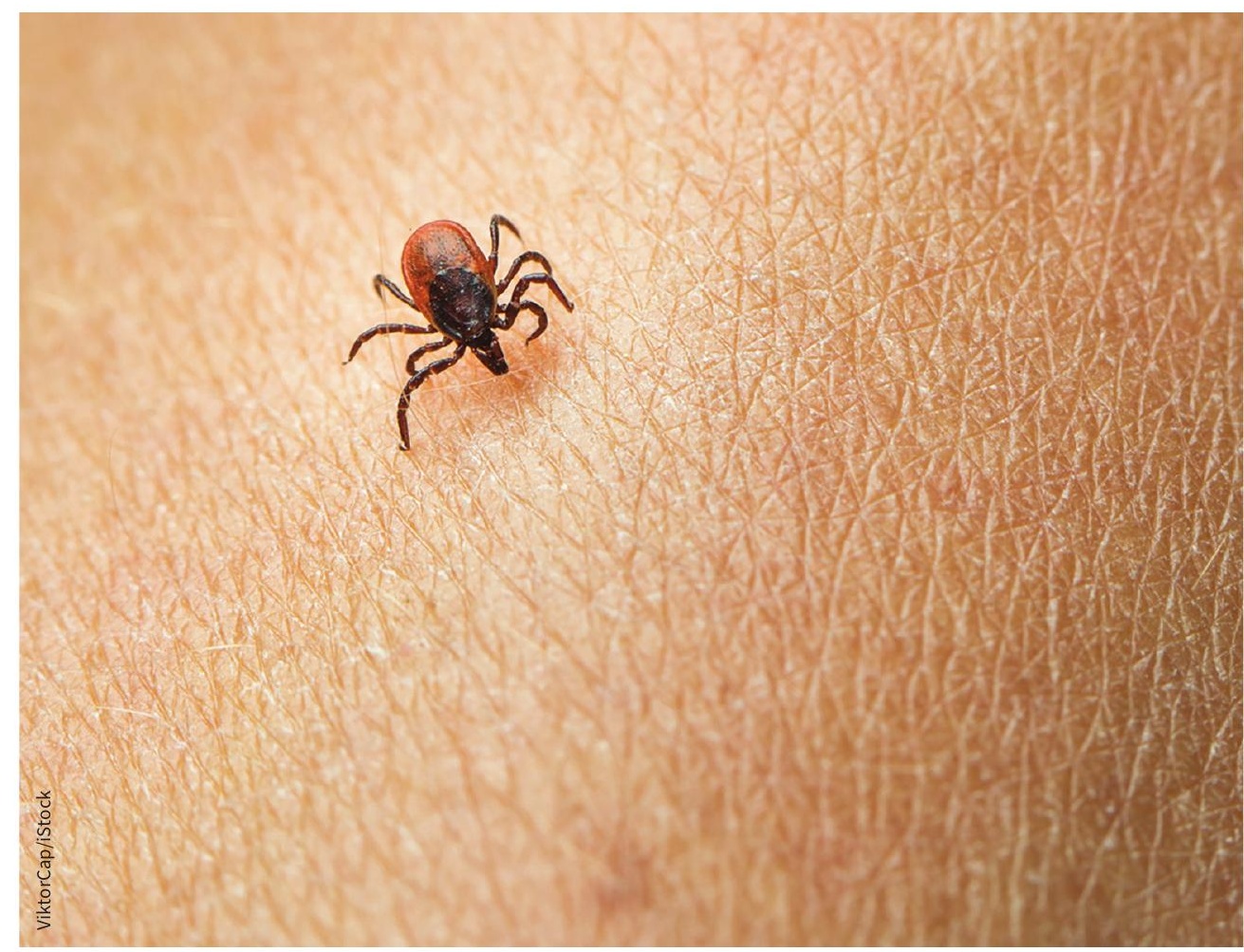

Reported cases of Lyme disease are on the rise in Canada.

the National Microbiology Laboratory and research funding from $\mathrm{CIHR}$, said Chief Public Health Officer Dr. Theresa Tam. The funding is mainly to support the network rather than to fund research, she said.

The network's research agenda "will be aimed at supporting the full aspect of the framework," Tam said. "It may inform where surveillance needs to go, how we best perform awareness - all those things could benefit from further research."

According to Moriarty, Canada lacks the research capacity to "figure out what Lyme disease is going to look like in Canada." She is hopeful the network will answer questions about the disease to help make predictions and to inform clinicians and the public.
Much of Canada's Lyme research to date has been done by PHAC's National Microbiology Laboratory. "I couldn't do any Lyme research independent of them," said Dr. Joanne Langley, professor of pediatric infectious diseases at Dalhousie University in Halifax. She recently completed a three-year study of Lyme disease in children across Canada in conjunction with the laboratory.

While the network will boost research collaboration, Langley said it will not solve the problem of the difficulty of getting CIHR grants. "It is difficult to get funds to research Lyme because it's difficult to get funds to research anything in Canada."

Carolyn Brown, Ottawa, Ont. 